January 2015

\title{
Insights Gained From a Cultural Contexts Counseling Course in a Rural Setting
}

Susan Dodd

St. Lawrence University, susandodd@gmail.com

Follow this and additional works at: https://digitalscholarship.unlv.edu/jpme

\section{Repository Citation}

Dodd, Susan (2015) "Insights Gained From a Cultural Contexts Counseling Course in a Rural Setting," Journal of Praxis in Multicultural Education: Vol. 9: No. 1, Article 4.

DOI: 10.9741/2161-2978.1075

Available at: https://digitalscholarship.unlv.edu/jpme/vol9/iss1/4

This Article is protected by copyright and/or related rights. It has been brought to you by Digital Scholarship@UNLV with permission from the rights-holder(s). You are free to use this Article in any way that is permitted by the copyright and related rights legislation that applies to your use. For other uses you need to obtain permission from the rights-holder(s) directly, unless additional rights are indicated by a Creative Commons license in the record and/ or on the work itself.

This Article has been accepted for inclusion in Journal of Praxis in Multicultural Education by an authorized administrator of Digital Scholarship@UNLV. For more information, please contact digitalscholarship@unlv.edu. 


\section{INSIGHTS GAINED FROM A CULTURAL CONTEXTS COUNSELING}

\section{Insights Gained From a Cultural Contexts}

\section{Counseling Course in a Rural Setting}

Research in the area of multicultural counselor education indicates that an increased cultural awareness of oneself and others is best supported in a program that infuses an emphasis on cultural competency throughout the curriculum and utilizes a variety of instructional approaches, particularly within the primary course on cultural contexts in counseling (Bemak, Chung, Talleyrand, Jones \& Daquin, 2011; Dickson \& Shumway, 2011; Ilieva \& Erguner-Tekinalp, 2012; Sharpe \& O’Connell, 2005). Although some research seeks to understand how counselors currently employ their knowledge of cultural differences while in the field (Packer-Williams, Jay, \& Evans, 2010), this leaves open the complete continuum of counselor preparation programs and courses, and does not take specific training practices into account. Other studies (Bemak, et. al, 2011; Dickson \& Shumway, 2011; Ockerman \& Mason, 2012;) emphasize the inclusion of a service-learning project into the counselor preparation program, which is helpful in culturally diverse geographic locations. However, there appears to be a lack of research of how to best provide these experiential learning activities in areas of the country that are racially homogenous. The counseling department on which this study is based, although located in a region with limited racial diversity, encourages students to utilize area and campus resources to maximize their cultural awareness.

The purpose of this study was to better understand preservice counselors' interpretations of and reactions to course readings and activities concerning social justice, race, and multicultural education. The learning activities within the cultural contexts course, to be described below, have been carefully planned over time by members of the department who are all very dedicated to issues of social justice. The geographical 


\section{INSIGHTS GAINED FROM A CULTURAL CONTEXTS COUNSELING}

location of the counseling program came into play during this planning process, as the census for the region has consistently remained at 93\% white (quickfacts.census.gov) with an estimated median household income of \$36, 691 in 2011(www.city-data.com). However, there is a Native American reservation within an hour's drive, as well as several campus organizations that are comprised of students who are racially and/or culturally unlike the majority of the region's permanent population. The racial demographics of the student population are still a $77 \%$ white, with $8 \%$ of the students being Hispanic/Latino, 6\% Black and 2\% Asian (www.collegedata.com). The graduate program did not reflect this level of diversity, but the students within the program could still see their races, cultures, sexual orientations, religious affiliations, etc. reflected in the greater campus community. Most students within the graduate program did not grow up in the immediate geographic area.

The aforementioned campus organizations often host educational and cultural events, which are viewed as optimal learning opportunities for students in the counseling program. The author taught the cultural context course every semester for three years, and included the same activities and course requirements each time. In order to assess the perceived effectiveness of these activities, the author deemed it necessary to follow up with prior students to determine which activities they felt were most helpful in their journey toward cultural competency. The participants in this study, who mostly identify as White and middle class, were asked to reflect on their level of cultural awareness prior to entering the course, as well as which activities created the most insight for them as they have entered into internships and professional working positions.

\section{Graduate Student Beliefs}




\section{INSIGHTS GAINED FROM A CULTURAL CONTEXTS COUNSELING}

Current research in multicultural education indicates that stand-alone college level courses may not substantively change student attitudes in a short period of time (Garmon, 2004; McDonald, 2005; Sleeter, 1995; Winitzky \& Barlow, 1998). Middleton (2002) found some of her college students to be "so strongly motivated by their existing beliefs that they chose not to explore some of the ideas presented in the course" (p.356).

Students are often attached to their beliefs, and only take in new information in a way that fits with prior assumptions (Adler \& Confer, 1998). In many cases, students find their prior beliefs are supported and possibly strengthened through the course, rather than having their beliefs broadened to include more diverse perspectives (Sleeter, 1995).

Research in the field of multicultural education provides ample evidence regarding the Eurocentric beliefs held by many students in the college classroom (King, 1991; Ladson-Billings, 2006; Lawrence \& Tatum, 2002). Many people from the dominant White and middle class culture have reached young adulthood without ever questioning the racial and classist biases entrenching most aspects of American society (King, 1991). A blind acceptance of prevailing racist and oppressive attitudes regarding everything from the individual capabilities of people of color to the macro-system of inequitable societal structures prevents these college students from grasping elements outside of the White middle class world (King, 1991).

The challenge for counselor educators is to assist students in their self-awareness as racial beings, and their power and responsibility to help eradicate racism. Many White, middle-class citizens are unaware of their own passive racism that has resulted from being raised in a Eurocentric society (Marx, 2001). It is quite an arduous task to gently confront these future professionals and help them to see outside their monocultural worldviews, and to help them understand that despite socioeconomic disparities, there is 
Journal of Praxisin M ulticultural Education, Vol. 9, No. 1 [2014], Art. 4

\section{INSIGHTS GAINED FROM A CULTURAL CONTEXTS COUNSELING}

still privilege associated with being white (McIntosh, 1988). Understanding that many counselors choose the profession because they truly want to help others (Marx, 2001; Milner, 2005), it is not surprising that the topic of racism in counseling is often met with resistance by these well-intentioned individuals (Marx, 2001).

Van Hook (2002) suggests that many multicultural education courses are not successful in changing student beliefs because these ingrained belief structures are not sufficiently challenged. Instead, students often enter such courses expecting to be edified on the cultural practices of a variety of diverse groups, rather than examine their own ingrained views of societal structures. Additionally, White privilege often creates "White defensiveness" on the part of White students who are not ready to have their beliefs challenged (Carpenter, 2000; King, 1991). Tatum (1992) delineates three factors that are often at the root of student resistance. The first is that many people believe that to discuss racial differences, especially in diverse groups, would come across as being racist. Second, many White professionals uphold the "myth of meritocracy," or the idea that the United States is a fair society and all individuals can succeed if they just work hard enough. There is the belief among some White individuals that as long as they are openminded and treat everyone equally, then racism is really not an issue. Tatum (1997) refers to White individuals who see themselves as "just normal" rather than belonging to a particular racial group. White people who have this mentality do not yet self-identify with Whiteness as a racial group, nor do they realize the implications of this form of identity development.

While the values of social justice are emphasized during the admissions day process for applicants of the counseling programs, students enter into the counseling programs at different levels of identity development. Because aspects of social justice are 


\section{INSIGHTS GAINED FROM A CULTURAL CONTEXTS COUNSELING}

so central to the programs, and because the number of applicants has historically been robust, applicants who seemed indifferent to these core values would likely not be admitted into the graduate school. Perhaps as a result of this application process, which included interview questions and small group discussions regarding issues of race, ethnicity and social justice, there were very few students within the counseling department who claimed they "did not notice racial differences". There were, however, times when white students seemed somewhat resistant to exploring aspects of their racial identity development, most often citing as a reason that the model "doesn't fit for them" or that "not everyone experiences this."

\section{Identity Development Models}

One assignment in this course was for each student to examine an identity development model that suited him or her the best. For most students taking the class, this was the Helms identity development model. Helms (1990) established a six status model for White identity development (see Appendex). The model is considered to have "statuses" rather than stages because each is not necessarily independent from the next (Helms, 1996). The first status is "Contact," wherein students have had little meaningful interactions with people of other races and may be unaware of any real racial issues. People in this stage often attest to being "color blind" (Milner, 2005; Tatum, 1992). Second is "Disintegration," where White individuals realize that racial inequalities do exist and continue to cause harm. It is logical that many students entering a multicultural course in Status One could be pushed to Status Two when provided with multitudes of data regarding the racial discrepancies during the course of the semester. The third status, "Re-Integration" is characterized by a reliance on feelings of White superiority (Hollins, 1999) and blaming the victim for the existence of racial inequalities. People at this status 
Journal of Praxisin M ulticultural Education, Vol. 9, No. 1 [2014], Art. 4

\section{INSIGHTS GAINED FROM A CULTURAL CONTEXTS COUNSELING}

may fall to this line of thinking after the startling realizations that occur in Status Two (Helms, 1990). It seems logical, then, that this transition to Status Three could also happen as a result of taking a multicultural class and experiencing the devastation and “self-annihilating process" through the upheaval of one's once stable world view (Thandeka, 2008). It is possible that the multicultural education courses that had limited results in enlightening student attitudes actually did impact students enough to push them to Status Three in their identity development, but did not provide for the students an avenue to the next stage of development. The higher statuses, which include PseudoIndependence, Immersion/Emersion, and Autonomy, involve a process of unlearning one's own racism, seeking out role models or "White Allies," and confronting racism on a daily basis.

\section{The Current Study}

After teaching this course for several consecutive semesters, the researcher felt the question of which course experiences were most meaningful and growth-provoking could best be answered by former students. Although the course evaluations at each semester's end for this particular class were overwhelmingly positive, the researcher sought to discover which particular activities the participants reflected upon the most since entering their internship or professional working experiences. The researcher also sought to explore how the students integrated the content of the multicultural course into their identities and which experiences they felt were most helpful in learning how to work with people who are racially or culturally unlike themselves. While many studies have examined student beliefs before and after taking a particular multicultural course, there is less consistent information regarding the process of change over time, when putting these practices into place. 


\section{INSIGHTS GAINED FROM A CULTURAL CONTEXTS COUNSELING}

The underlying research questions of this study were as follows:

One: How would students rate their level of cultural competency prior to taking this class and how would they rate it now? Why?

Two: Were there any activities and/or experiences that participants feel changed the way they view and/or interact with people unlike themselves? If so, what were they?

Three: What activities and/or experiences do participants feel impacted them the most while enrolled in this class and in what way?

Four: What activities and/or experiences do participants feel they have reflected on the most during the time since taking this class and why?

Five: Are there any aspects of this course that participants feel impact them on a regular basis? If yes, in what way?

Additionally, participants were asked how they self-identity, length of time since taking the course, and about their current work setting.

\section{Method}

The purpose of the study was to determine the lasting influence of a multicultural cultural contexts course on participants taking the class during a specific time period and with the same instructor. It is the author's intention to gain a better understanding of the impact of her own teaching methods within the context of working in a racially homogenous and rural setting, rather than to make generalizations to other populations. The author employed a qualitative case study approach utilizing post-hoc analysis as she searched for similarities in participant responses regarding the class activities that seemed to create the greatest impact in regard to cultural awareness and growth. A constant comparative form of analysis 
Journal of Praxisin M ulticultural Education, Vol. 9, No. 1 [2014], Art. 4

\section{INSIGHTS GAINED FROM A CULTURAL CONTEXTS COUNSELING}

was used to illuminate themes between participant responses in regards to the most beneficial class experiences.

\section{Participants}

This study took place at a state university in a rural location in the Northeast United States. The seven participants were former graduate students enrolled in a cultural contexts in counseling course, each taught by the same instructor, between 2009-2012. The author contacted 25 former students via email and explained the purpose of her study. Although there had been more students who had taken the course, there was not a current email on file for them within the counseling department. The researcher asked via email for willing participants to respond if they were interested in providing feedback on the course activities. Nine former students responded with an expressed willingness to participate in the study, and seven of them completed the response questions. Four participants identified as female and three as male. Six identified as White or of European descent, while one female identified as Black, with Caribbean descent. One participant identified himself as homosexual, another as lesbian, and another as bisexual. The other four participants did not mention their sexuality when asked, "How do you identify yourself?" Only one participant included religion (Catholic) as a part of this response. The age range of the participants was 24 to 38 years, with the median age being 30 years. The cultural contexts course that was paired as a co-requisite with a pre-practicum course that required the students to practice their counseling skills with a class partner.

Additionally, the course was part of a (CACREP) program, where cultural contexts were embedded throughout all courses in the counseling program. The author identifies as a heterosexual White female in her late 30s.

\section{Course Design}




\section{INSIGHTS GAINED FROM A CULTURAL CONTEXTS COUNSELING}

The course provided an introduction to the influence of cultural differences during the counseling process. The objectives outlined in the syllabus described a course where students reflect on their own experiences and actively engage in discussions of racial and cultural issues both in class and through later reflections on weblogs. The author added weblog discussions to this pre-existing course to provide an extension of class discussions. As found by Ilieva and Erguner-Tekinalp (2012), the added element of online discussions is ideal for the often delicate and emotionally charged conversations involving racism and discrimination. Students who may hesitate to speak up in class, for whatever reason, are provided an opportunity to reflect on their thoughts and type them out, without fear of interruption. Students also seem "less exposed" in sharing their feelings and opinions in the online forum, despite the fact that the writer's identities are apparent to their classmates (Ilieve \& Erguner-Tekinalp, 2012, p. 10) The reading material required for this course included, among others, topics such as White privilege, racism, social class, ablism, sexual identity and discrimination, language diversity, ageism and adultism. As previously described, this class was taken as a co-requisite with a pre-practicum class, where students continued to learn and hone their counseling skills. Aside from class discussion and reading assignments from the texts, other assignments in the class included:

The peer counseling component: The primary requirement of this counseling assignment was for students to talk with their peer counselor about any topic related to culture, race, class, sexual identity, etc. The purpose of this assignment was to have students openly explore issues related to these topics with which the individual students may be struggling. Each dyad video recorded six weekly counseling sessions, held in the department's counseling lab, lasting approximately one hour each. The student 


\section{INSIGHTS GAINED FROM A CULTURAL CONTEXTS COUNSELING}

counselors then met privately with the class instructor for supervision and feedback on counseling skills used throughout the session. Student growth was measured throughout this process by instructor observation of improved counseling skills, as well as by selfrating evaluations and reflection papers written by students about insights gained during the process of counseling another person in regards to cultural concerns.

Interviews with 8 individuals unlike yourself: The course syllabus contained the following list of identifiers:
a. an African-American
b. an Asian-American
c. a European-American
d. a Latino or Latina
e. a Native-American
f. a person who is openly gay or lesbian or bisexual or transgendered
g. a person with a visible disability
h. a person who is over 70 years of age
i. a person not of your biological sex
j. a person who espouses commitment to a particular religion or spiritual perspective that is not the same as yours
k. a person who was not born in the U.S.
1. a person who is significantly over- or underweight

Students were asked to select eight of the 12 people on the list with whom to conduct an interview. The interviewee could not be someone within the counseling department, and could not be a close friend or relative of the interviewer. Students were required to hand in their interview questions, along with a transcript of each interview. At the end of the semester, students were required to write a reflection paper based on the collective interview process. As students reviewed this assignment on the first day of class and realized they would be required to approach strangers and ask questions about their racial or cultural experiences, the resulting anxiety and/or resistance was often palpable within the classroom. Some students would immediately state that this activity would be impossible for them to complete, as they did not know many people who fit these descriptors, or that they did not have the time 


\section{INSIGHTS GAINED FROM A CULTURAL CONTEXTS COUNSELING}

to locate such individuals and conduct interviews. Students would often verbalize a discomfort with the prospect of approaching others to talk about issues such as race or culture. However, as will be discussed, this activity is the one that appears to have the greatest impact on the participants involved in this study. Throughout the semester as the interviews were being conducted, students were asked to share their interview experiences with the class. While keeping the interviewees' identities confidential, students shared with their classmates basic descriptors of whom they interviewed, as well as their own feelings throughout the interview process. This sharing process created a vicarious learning experience for the class, and also provided a more diverse pool of responses than what only one interview can provide. For example, students were able to recognize, "Oh your White male interviewee did not have the same feelings/ideas/responses as mine did," which emphasized the differences that exist within cultural groups.

Cultural Collage: For this project, students used everyday objects (e.g., magazine cutouts, photos) to create a social justice collage that represented the most salient aspects of their identity (e.g., race/ethnicity, gender, sexual orientation) and journey of personal advocacy that shaped how they view social justice theory, the nature of human challenges and resilience, and the reasons they have chosen to become a counselor. Students were then asked to make a brief class presentation of their creations during the last days of the semester. Because this assignment was so open-ended, many students became very creative in their approach. For example, one student demonstrated how making a pie encompassed his cultural heritage. He brought the ingredients into class and likened each one to a part of himself as he poured them into the bowl. He then made the pie and shared it with the class, illustrating his cultural value in sharing food with others. Another 
Journal of Praxisin M ulticultural Education, Vol. 9, No. 1 [2014], Art. 4

\section{INSIGHTS GAINED FROM A CULTURAL CONTEXTS COUNSELING}

student played the banjo, while another created a box that was decorated with song lyrics, photos, and other elements of herself that she found valuable. In the three years of teaching this class, all students appeared to be actively engaged in this assignment. Each semester as students shared very openly about themselves during this presentation, the instructor was consciously aware of the deep privilege she had in being part of this intimate sharing and always expressed gratitude to the students for their honesty and candor.

Cultural Immersion Activities: Attend and actively participate in at least three activities outside of class that offer the opportunity to engage in, be a participant-observer in, and immerse oneself in social/educational activities outside their typical comfort zone. As stated before, this often involved attending a campus event or a visit to the nearby reservation. Many students also elected to attend a religious service for a denomination or sect outside of their own beliefs.

\section{Assessment of racial identity development following one of the identity development}

models: As previously stated, students were asked to complete this assignment following class discussions and readings in the text pertaining to the various identity development models.

Multicultural Audit: Students were asked to conduct an audit of their 15 closest friends, and identify them based on race, gender, sexuality, religion and social class. The directions for this activity are as follows:

Conduct a multicultural audit of your life, identifying the 15 persons with whom you are closest (other than family) with respect to the cultural identifiers of sex, race, religion, ability, sexual orientation, and socio economic status. Include yourself as noted at the 


\section{INSIGHTS GAINED FROM A CULTURAL CONTEXTS COUNSELING}

bottom. Then place each person (using the number assigned to them on the form) within the concentric circles - the page labeled Multicultural Audit - Part Two, placing those with whom you are closest in the inner circles, those with whom you are less close farther out. Review the outcomes of your audit with respect to the level of heterogeneity/ homogeneity of those with whom you hold your closest relationships - to what degree, and with regard to which cultural identifiers are they most like you? like each other? Write a 3 - 5 page paper responding to these questions; include both parts of the multicultural audit when you submit your paper.

Students often wrote about the insight they gained when considering their relationships through this lens.

Student Weblogs: Student weblogs were a weekly course requirement for students to post their responses to class discussions and also to comment on their classmates' weblogs. This ensured an online dialogue between students, unlike the classroom setting where students may not have the opportunity to vocalize their thoughts. The instructor reviewed the weblogs and used the content to inform class discussions and activities, but only interjected intermittently, allowing a more student-directed atmosphere for weblog discussions. This provided a different dynamic because students who are writing in a journal to be read by a professor may be more self-conscious when expressing true feelings regarding course activities and class experiences.

Videos Watched in Class: The author used video clips in instruction on a weekly basis. These included an occasional hour long documentary on topics such as transgender issues, to the more often brief video clips to illustrate a point being discussed in class. One full class was devoted to the topic of "deconstructing media," where students viewed commercials and clips from popular children's movies to discuss topics such as: how are 
Journal of Praxis in Multicultural Education, Vol. 9, No. 1 [2014], Art. 4

\section{INSIGHTS GAINED FROM A CULTURAL CONTEXTS COUNSELING}

women and other minorities portrayed? Whose voices are heard and whose are left out?

What are the impacts of these stereotypes when viewed by the intended audience of young children?

\section{Procedures}

As previously described, the author contacted former students via email, described the premise of the study, and asked for an emailed response from anyone who was interested in participating. For the nine students who responded, the researcher explained that although individual responses would be identifiable to her, they would be combined into group format for purposes of the study. Participants were provided with a list of course activities and the aforementioned research questions. All correspondence took place via email. Once all responses had been received, student names were removed and all data was transferred into a Word document. Utilizing grounded theory, the student responses were reviewed and coded for themes using constant comparative analysis (Merriam, 1998).

\section{Findings and Discussion}

Research Question One: How would students rate their level of cultural competency prior to taking this class and how would they rate it now? Why?

Three participants rated themselves as having a low level of cultural competency prior to taking the class, and having a medium level of competency at the current time. The other four participants indicated that they began the course with a medium or high medium level of cultural competence at the beginning of the course and are all at higher levels at the time of this study. Their reasons for this change included class activities and, for two students who are now employed as counselors, current work experience with historically marginalized populations. Several students mentioned having a lack of 


\section{INSIGHTS GAINED FROM A CULTURAL CONTEXTS COUNSELING}

exposure or thought to cultural issues prior to entering the course. Most also indicated an increased awareness of their own privileges and biases as a result of their work in this class. As one White female participant noted,

"I think that I may have thought (my cultural competence) was higher than it was. It was probably medium. After taking (this class) it was probably higher medium to lower high. Before the class, I had thought more about cultural diversity in terms of race. Although being from a low SES family, being a woman, and sexual orientation had been a part of my diverse experience, I had not thought of this as much in terms of cultural diversity. Although I saw inequities in the lives of my students of different races, I had not thought about my own privilege as much or how I may unknowingly contribute. I am also better able to address bias when things are said or done by others. I am better able to check my own bias and privilege."

Another participant reflected on specific course activities that enlightened her during the semester. She reflected,

"Prior to this class I would say my competency was about medium going into high due to being in (a mostly White, rural environment) for 4 years. After taking this class I would say it's high due to the racial identity model assignment. I got a chance to explore the phases I went through and felt more comfortable knowing that I was not the only person going through a similar process. Also, doing the peer counseling I learned that there are other isms that can be related to others regardless of race. For example, I had some classism issues which stereotypically people would not know 


\section{INSIGHTS GAINED FROM A CULTURAL CONTEXTS COUNSELING}

because I am Black.”

Overall, all participants indicated an increased level of awareness and competency as a result of taking this class.

Research Question Two: Were there any activities and/or experiences that participants feel changed the way they view and/or interact with people unlike themselves? If so, what were they?

All participants responded by mentioning the impact that the interviews had on them as cultural beings. The following quote by a White female participant summarizes the sentiment expressed by many of the respondents:

"The interviews, although awkward when approaching those I did not know, allowed me to think of things that I had not previously thought about. I had a sense of various inequities, but got a better sense of how this may play out in people's lives. The interviews allowed me to hear about micro-aggressions that I may not have been aware of. It helped me to try to pay even more attention to my own behavior, thoughts, bias, etc. It also gave me a sense that I would be a part of the problem if I do not address such things when I see it happening."

As another White female participant responded, "The multicultural interviews were particularly helpful in learning about other populations' experiences. The interviews illuminated other populations' struggles in a way that readings simply cannot." Although a couple of participants mentioned the cultural collage and others remarked on the immersion experience, there was $100 \%$ agreement on the growth impact of the interview assignment. 


\section{INSIGHTS GAINED FROM A CULTURAL CONTEXTS COUNSELING}

Research Question Three: What activities and/or experiences do participants feel impacted them the most while enrolled in this class and in what way?

Although the responses for this question varied and three respondents mentioned the interviews, four participants spoke about their growth as a result of the class discussions. As one male participant stated, "The class discussions were certainly eye opening. I felt the effect of the discussions for days, some were a bit intense." This intensity he references was echoed in the responses from the other students who mentioned the impact of the class discussion. Another participant referenced the lingering effect of these conversations in the following statement:

"The class discussions and multicultural interviews impacted me the most. I know they impacted me because they continue to inform my work with populations that differ from my own. They also continue to inform how I choose to live my life- with whom I associate, when I speak out against injustice, and how I choose to advocate for others who cannot advocate for themselves." (White female)

Other participants expressed their surprise at the amount of "White defensiveness" that became apparent during class discussions. This element of the class was enlightening even for White students who had never considered their privilege prior to entering the class. An important aspect to note here is that the class composition varied each semester, which likely had an impact on many aspects of the class discussions between courses. For example, one class consisted of six white females, but there was diversity within the group in terms of socio economic status, sexual orientation, religion, and age. In that particular class, those topics became more salient in our discussions than race and ethnicity, which were more prominent points of discussion in most of the other classes. In 


\section{INSIGHTS GAINED FROM A CULTURAL CONTEXTS COUNSELING}

all the classes, students shared the stories of their interviewees, as well as their reflections on each interview experience. This provided the class with real examples of the lives of "others," and it also allowed for discussions regarding the similarities and differences within populations, based on the individual responses of those who chose to participate in the interviews (students were very rarely turned down). Overall, the class discussions appear to have been helpful in promoting student awareness and growth.

Research Question Four: What activities and/or experiences do participants feel they have reflected on the most during the time since taking this class and why?

The responses here did reflect some variation, with a couple of participants mentioning the deconstructing media and White privilege components of the course, but the majority focuses again on the interviews and class discussions. As one White female participant stated,

"The experiences I have reflected on the most have probably been the interaction between the counseling component and the interviews. Through the counseling component I had thought more about my own identity, being true to myself, and others definitions/perceptions of me. Sometimes I felt I was living as others viewed me, rather than my true self. With the interviews, I learned about other perceptions that I might not have been aware of for others. This has made me think a lot about authenticity, both my own and others and what may be barriers from being authentic. I think that this can affect everyday interactions between people and is something I try to be aware of when working with others. I think that this also gets back to recognizing my own privilege and how that can affect others (and myself). “ 


\section{INSIGHTS GAINED FROM A CULTURAL CONTEXTS COUNSELING}

This statement reflects a shared sentiment expressed by several of the participants that learning the perspectives of other people had a lasting impact beyond the confines of the semester. All participants appeared deeply reflective in regard to this element of the course.

Research Question Five: Are there any aspects of this course that participants feel impact them on a regular basis? If yes, in what way?

Although the responses here were again varied, most participants reflected on the insight they gained in regard to their own privilege and self-awareness as cultural beings. Three of the participants again referenced the powerful impact of the interviews, and how these served as a helpful experience in talking to others about issues of racism and discrimination. As one participant stated,

"I think that the intimacy of the class, the sharing of thoughts, and the pushing myself out of my comfort zone are carried with me. I was somewhat uncomfortable with the interviews, but now see it as a launch pad to engaging in interactions with people in every day life." (White female)

Based on the responses to the research questions in this study, the impact of the interview component of this class cannot be underestimated. This activity seemed to create the most initial anxiety for students, but also appears to be the most transformative class experience. In some cases, students became rather resistant to the idea of participating in this activity, and verbally expressed reasons why they could not participate when the assignment was discussed on the first day of class each semester. Although none of the participants of the current study exhibited outward displays of resistance, one theme that was common 
Journal of Praxisin M ulticultural Education, Vol. 9, No. 1 [2014], Art. 4

\section{INSIGHTS GAINED FROM A CULTURAL CONTEXTS COUNSELING}

among their responses was a feeling of nervousness related to interviewing strangers about topics which could be personal or sensitive. All participants indicated an increased sense of awareness as a result of the interview process. This particular activity seems to be an ideal solution for a counseling program that is geographically situated in a mostly White, rural area. While there is abundant research to support the use of service learning projects, particularly in urban environments (Dotson-Blake, Dotson, Glass \& Lilley, 2010; Wilczenski \& Schumacher, 2008), a service learning project in the immediate area may be limited in exposing the counseling students to a wide variety of cultural difference, all students were able to locate at least eight people unlike themselves to interview as part of the class requirement. As evidenced in the participant responses throughout this paper, the impact of this experience was long-lasting and appears to have assisted the students in their cultural awareness and growth.

The other elements of the class that seemed to have a lasting impact on the students included the class discussions and the cultural immersion and collage assignments. Several participants also remarked that the conglomeration of all the class experiences seemed to propel them forward, rather than one or two activities in isolation.

\section{Limitations of Study}

The sample size of this study was rather small. Out of about 25 former students who were contacted, (10 former students could not be located), only nine responded with an interest to participate in the study and two students did not complete the study. Furthermore, the seven participants were volunteers, which may indicate some qualitative difference between those students and other classmates who did not volunteer to 


\section{INSIGHTS GAINED FROM A CULTURAL CONTEXTS COUNSELING}

participate in the study. Also, based upon the author's memory of student behavior in class, the responding participants enjoyed the class and not did exhibit much resistance during the class.

Researcher bias was also a possible limitation. The author, who was also the instructor of this class, was raised in the United States with the perspective of a White middle-class female, which certainly had impact on how the class was taught. It is therefore a challenge not to overlook any comments or viewpoints of people who have experienced the world from a similar frame of reference.

Finally, it is not possible to meter out the experiences in student lives since taking the course, and how these may impact the ways in which these graduates now reflect on their class activities from the past.

\section{Recommendations for Future Research}

The aforementioned concerns regarding sampling and the specifics of this rural setting should be addressed in future studies. The strongest finding in this study is the emphasis the former students placed on the interviewing activity and the intrapersonal changes they experienced as a result of this process. The inclusion of an interview assignment in counseling classes in similar geographic locations, with follow up surveys and observations of the students after graduation could yield information on how students reflect on the multicultural course in light of insights gained from time in the actual classroom and life experiences after the course. Another recommendation is to replicate the theoretical and methodological aspects of this study with other diversity courses utilizing similar educational techniques. Any similarities in meaningful learning experiences expressed by the students can then be emphasized in future courses. 


\section{INSIGHTS GAINED FROM A CULTURAL CONTEXTS COUNSELING}

\section{Implications for Multicultural Educators in Rural Settings}

Based on information gained from student applications to the counseling program, many students entered into the program without a lot of experience or time spent outside of a mostly White, rural setting. While a given community may not host a lot of opportunity for a heterogeneous racial experience, most college campuses offer a plethora of racial, cultural, and religious events throughout the year, where many students can learn about groups unlike those with which they most closely identify. Asking students to conduct individual interviews creates an intimate experience for the student to learn about others without the need for a large heterogeneous population.

A final implication for cultural contexts educators is that of congruence across courses in a multicultural approach to education. As previously stated, one course is not enough to alter a lifetime of experiences and worldviews regarding race and racism. Although the questions asked as part of this study pertained only to the one course in particular, the students were constantly learning about cultural contexts in counseling through their other coursework in the program. 


\section{INSIGHTS GAINED FROM A CULTURAL CONTEXTS COUNSELING}

\section{References}

Adler, S. C. \& Confer, B. J. (1998). A practical inquiry: Influencing preservice teachers’ beliefs toward diversity and democracy. College and University Faculty Association of the National Council for the Social Studies. Anaheim, CA.

Bemak, F., Chung, R., C., Talleyrand, R. M., Jones, H. \& Daquin, J. (2011). Implementing multicultural social justice strategies in counselor education training programs. Journal for Social Action in Counseling and Psychology, 3(1), $29-43$.

Carpenter, A. (2000). An ethnographic study of preservice teacher resistance to multiculturalism: Implications for teaching. American Educational Research Association. New Orleans, LA.

College Data: Your Online College Advisor (n.d.) Retrieved from collegedata.com

Dickson, G. L. \& Shumway, B. A. (2011). A framework of multifaceted approaches to multicultural training. Retrieved from http://counselingoutfitters.com/vistas/vistas11/Article_69.pdf

Dotson-Blake, K. P., Dotson, L. K., Glass, J. S., \& Lilley, B. D. (2010). Accountability in Action: Service-Learning Partnerships in Practice. Journal of School Counseling, 8.

Garmon, M. A. (2004). "Changing preservice teachers' attitudes/beliefs about diversity: What are the critical factors?" Journal of Teacher Education, 55, 201-213.

Helms, J. E. (1990). Black and White racial identity: Theory, research, and practice. New York: Greenwood. 


\section{INSIGHTS GAINED FROM A CULTURAL CONTEXTS COUNSELING}

Hollins, E. R. (1999). Assessing teacher competence for diverse populations. Theory into Practice, 32(2), 93-99.

Ilieva, V. \& Erguner-Tekinalp, B. (2012). Computer applications in counselor education: Developing cultural competencies through online collaboration of future school counselors. Canadian Journal of Learning and Technology, 38(2), 1-17.

King, J. E. (1991). Dysconscious racism: Ideology, Identity, and the miseducation of teachers. Journal of Negro Education, 60, 133-145.

Ladson-Billings, G. (2006). It's not the culture of poverty, it's the poverty of culture: The problem with teacher education. Anthropology and Education Quarterly, 37(2), 104-109.

Lawrence, S. M \& Tatum, B. D. (2002). White racial identity and anti-racist education: A catalyst for change. In Beyond heroes and holidays. (pp.45-51) Teaching for Change: Washington, D. C.

Marx, S. (2001). How whiteness frames the beliefs of white female pre-service teachers working with english language learners of color. AERA. Seattle, WA.

McDonald, M. A. (2005). "The integration of social justice in teacher education: Dimensions of prospective teachers' opportunities to learn." Journal of Teacher Education, 56, 418-435.

McIntosh, P. (1988). White privilege: unpacking the invisible knapsack. In Lee, E., Menkart, D., \& Okazawa-Rey, M.(eds.) Beyond heroes and holidays (pp. 77-80). Washington, DC: Teaching for Change.

Merriam, S. B. (1998). Qualitative research and case study applications in education. San Francisco: Jossey-Bass.

Middleton, V. A. (2002). "Increasing preservice teachers' diversity beliefs and 


\section{INSIGHTS GAINED FROM A CULTURAL CONTEXTS COUNSELING}

commitment." The Urban Review, 34, 343-361.

Milner, H. R. (2005). "Stability and change in US prospective teachers' beliefs and decisions about diversity and learning to teach." Teaching and Teacher Education: An International Journal of Research and Studies, 21, 767-786.

Ockerman, M. S. \& Mason, E. C. M. (2012). Developing school counseling students' social justice orientation through service learning. Journal of School Counseling, $10(5), 1-26$.

Packer-Williams, C. L., Jay, M. L., \& Evans, K. M. (2010). Understanding the contextual factors that influence school counselors' multicultural diversity integration practices. Journal of School Counseling, 8, 1-34.

Sharpe, M. J. \& O’Connell, W. P. (2005). An ecological model for counselor pedagogy incorporating service learning. Journal of College Teaching \& Learning, 2 (8), $15-24$.

Sleeter, C. E. (1995). An analysis of multicultural education. In J. A. Banks, \& C. M. Banks (Eds.), Hankbook of research on multicultural education (pp. 81-94). New York: Macmillan.

Tatum, B. D. (1992). Talking about race, learning about racism: The application of racial identity development theory in the classroom. Harvard Educational Review, 62, $1-24$.

Tatum, B. D. (1997). Why are all the black kids sitting together in the cafeteria? New York: Basic Books.

Thandeka (2008). The cost of Whiteness. In K. E. Rosenblum \& T. C. Travis (Eds.), The meaning of difference: American constructions of race, sex and gender, social class, and sexual orientation (pp. 315-330). Boston: McGraw-Hill. 


\section{INSIGHTS GAINED FROM A CULTURAL CONTEXTS COUNSELING}

Van Hook, C. (2002). Preservice teachers' perceived barriers to the implementation of a multicultural curriculum. Journal of Instructional Psychology, 29, 254-264.

Wilczenski, F. L., \& Schumacher, R. A. (2008). Service Learning Integrated in Urban School Counselor Preparation. Journal of School Counseling, 6(12), n12.

Winitzky, N. \& Barlow, L. (1998). Changing teacher candidates' beliefs about diversity. American Educational Research Association. San Diego, CA. 


\section{INSIGHTS GAINED FROM A CULTURAL CONTEXTS COUNSELING}

\section{Helms’ Identity Development Model}

Status One: Contact. People in this stage have had little meaningful contact with people of other races and may be unaware of any real racial issues. People in this stage often attest to being “color blind” (Milner, 2005; Tatum, 1992).

Status Two: Disintegration. It is during this stage the White individuals realize that racial inequalities do exist and continue to cause harm.

Status Three: Re-Integration. This status is characterized by a reliance on feelings of White superiority (Hollins, 1999) and blaming the victim for the existence of racial inequalities. According to Helms (1990), people at this stage of the identity model are more susceptible to peer pressure and could be encouraged to this line of thinking after the startling realizations that occur in Status Two.

Status Four: Pseudo-Independent. Individuals in this stage of development make a conscious decision to unlearn their own racism, although they may not be cognizant of the most effective ways of doing so.

Status Five: Immersion/Emersion. People in this stage can find role models who are secure in their White identities and are successful in fighting the problems of racism.

Status Six: Autonomy. Individuals in this stage are committed to confronting racism on a daily basis. 